\title{
Vocación y vocaciones
}

1

Nuestro último retiro, adviento de 1981, estuvo dedicado a reflexionar sobre la «vocación y el seguimiento de Cristo». Una temática, cuyo valor se desprende fácilmente del mismo título. Trascendental, para la vivencia de nuestro compromiso cara al mundo y cara a la Iglesia. Difícilmente se podrá encontrar algo tan vital para nuestra vida religiosa. Con todo, y esto son matices en verdad, pero matices muy interesantes, fue una temática orientada principalmente, aunque no exclusivamente, desde una perspectiva intrínseca. Es decir, desde los valores que se desprenden de su misma realidad, sin insistir demasiado en nuestro contexto histórico particular.

Ahora las cosas cambian de signo. Manteniendo los valores apuntados, se quiere ahora constatar y resaltar la trascendental importancia que tiene para nosotros y la vivencia de nuestra vocación el complejo mundo moderno que nos toca vivir. El principio básico de esta actitud lo formula la GS en los siguientes términos: «es propio de todo el pueblo de Dios, pero principalmente de los pastores y teólogos, auscultar, discernir e interpretar, con la ayuda del Espíritu Santo, las múltiples voces de nuestro tiempo y valorarlas a la luz de la palabra divina, a fin de que la verdad revelada pueda ser mejor percibida, mejor entendida y expresada de forma más adecuada» ${ }^{1}$. Esta nueva sensibilidad la formula asi un teólogo moderno: «antes existía una especie de tendencia dirigida a superar lo que podían parecer imperfecciones de la experiencia: su temporalidad, su limitación y cambios. Daba la impresión de que el saber se hallaba necesariamente abierto hacia otro nivel de inmutabilidad y suprahistoria. Ahora pensamos que no existe otro lugar de entendimiento y de saber que la experiencia realizada como historia. Sólo en un proceso de experiencia, en un contacto vital con el contexto o medio en que se encuentra, el hombre escucha y crea» ${ }^{2}$.

1. Vaticano II, GS, 44b.

2. PikazA, X., Experiencia religiosa y cristianismo. Sígueme, Salamanca 1981,70. 
2

Vocación y vocaciones quiere hacerse eco de una inquietud, que nos afecta de una forma muy directa y muy profunda. Se trata del grave problema de la falta de vocaciones. Todos constatamos con angustia su escasez. La consecuencia inmediata es que, como comunidad, nos vamos muriendo poco a poco. Nuestra comunidad, con una media edad superior a los 56 años, es una comunidad vieja. El problema es grave en sí. Pero es necesario verlo sin dramatismos. Pero, sobre todo, es necesario plantearlo con objetividad e hidalguía. No se trata simplemente, aunque ello es importante, de sobrevivir a cualquier precio. Se trata, eso sí, de alcanzar una sobrevivencia que esté mantenida por unos ideales evangélicamente válidos para nuestro mundo moderno. $Y$ subrayo estas últimas palabras, porque la fuerza del argumento está precisamente en ellas. $Y$, de entrada, hemos de reconocer que no es válido el simple hecho de sobrevivir. Una sobrevivencia, sin más aval que la misma sobrevivencia, sería éticamente injustificable. Si no tenemos algo válido que ofrecer a quienes pueden seguir nuestro camino, entonces hay que aceptar la muerte como último y generoso recurso. Juan Bautista Metz habla, desde esta perspectiva, del carisma de morir para las comunidades que han agotado la fuerza de su testimonio. Morir no es, en el fondo, nịgún deshonor, cuando no haya razones para vivir. Puede ser un auténtico carisma, según la expresión de Juan Bautista Metz ${ }^{3}$.

Con todo, la aceptación de la posibilidad de morir no es, de suyo y sin más, la solución aceptable. Es necesario poner todos los medios justos $y$ legítimos, para impedirlo. La muerte adviene, de ordinario, cuando se han agotado todos los recursos.

Este retiro está enmarcado en el contexto antes reseñado. Es preciso que todos tomemos conciencia del problema, con el fin de darnos cuenta que la tarea afecta a todos, aunque en la comunidad haya algunos especialmente encargados de las vocaciones.

El problema afecta a todos. Se parte de aquí. Para alcanzar, en este campo concreto, soluciones viables, es necesario considerar algunos puntos. Ellos nos ayudarán, deben ayudarnos, a vivir nuestra vocación de forma más plena y evangélica.

El primer punto a tener en cuenta es la necesidad que todos tenemos de

3. Cf. METz, J.B., Las órdenes religiosas. Herder, Barcelona 1978,21. 
trabajar por las vocaciones. La necesidad de este trabajo viene expresada, a nivel de autoridad, por algunos indicadores. Comencemos por recordar uno muy significativo: el Concilio Vaticano II. «El deber de fomentar las vocaciones pertenece a toda la comunidad cristiana, que debe procurarlo, ante todo, con una vida totalmente cristiana; ayudan sobre todo a esto las familias, que, llenas del espíritu de fe, de caridad y de piedad, son como el primer seminario, y las parroquias, de cuya vida fecunda participan los mismos adolescentes. Los maestros y todos los que de algún modo se consagran a la educación de los niños y de los jóvenes, $y$, sobre todo, las asociaciones católicas, procuren cultivar a los adolecentes que se les han confiado, de forma que éstos puedan servir y seguir con buen ánimo la vocación divina. Muestren todos los sacerdotes un grandísimo celo apostólico por el fomento de las vocaciones y atraigan el ánimo de los jóvenes hacia el sacerdocio con su vida humilde, laboriosa, amable, y con la mutua caridad sacerdotal y la unión fraterna en el trabajo» ${ }^{4}$.

Lo que se dice de forma general de toda la comunidad cristiana y de la vocación al sacerdocio en concreto, nos compromete particularmente a nosotros como comunidad religiosa. $Y$ nos compromete particularmente, porque, en la base de nuestra vida religiosa, tiene que estar el convencimiento de que ella sigue siendo un modo válido de encarnar el seguimiento de Cristo. Sin esta perspectiva, nuestra presencia aquí carecería de sentido. Es verdad que nuestro horizonte religioso no se circunscribe sólo al tema de las vocaciones sacerdotales. La vocación religiosa tiene densidad por sí misma. Pero el hecho concreto es que casi todos nosotros o somos presbíteros o aspiramos a serlo. Nuestro compromiso, si se tiene en cuenta la condición de nuestra vida religiosa, abarca la doble perspectiva: la religiosa y la sacerdotal. Por ello, las palabras del Concilio pueden servir muy bien de punto de referencia, de toque de llamada en el campo concreto de las vocaciones.

Si ahora, para proceder con un poco de orden, desglosamos el problema, se verá cómo el mecanismo de desarrollo es idéntico. Estamos hablando sobre el convencimiento que debemos tener acerca de nuestra vida religiosa, como modo válido de encarnar el seguimiento de Cristo. No es fácil mantener, en ocaciones, este convencimiento, pues es indiscutible que la crisis sigue afectándonos todavía en mayor o menor intensidad. Para superar el pesimismo que fácilmente se nos puede filtrar, será siempre preciso volver a recordar y meditar los valores de la vida que hemos escogido desde una vivencia de fe. No podemos quedarnos aquí. De ello se hablará más adelante. Pero es un punto de partida absolutamente necesario. Para ello, acudimos de nuevo

4. VATICANO II, OT, 2a. 
al Vaticano II, cuyo valor, a nivel incluso de autoridad técnica, es indiscutible, pues intentó acercarse al máximo a los problemas de nuestro tiempo. "Los consejos evangélicos, castidad ofrecida a Dios, pobreza y obediencia, como consejos fundados en las palabras y ejemplos del Señor y recomendados por los apóstoles, por los padres, doctores y pastores de la Iglesia, son un don divino que la Iglesia recibió del Señor, y que con su gracia se conserva perpetuamente... Esas familias ofrecen a sus miembros todas las condiciones para una mayor estabilidad en su modo de vida, una doctrina experimentada para conseguir la perfección, una comunidad fraterna en la milicia de Cristo y una libertad mejorada por la obediencia, en modo de poder guardar fielmente $y$ cumplir con seguridad su profesión religiosa, avanzando en la vida de caridad con espíritu gozoso" ${ }^{5}$.

"La santidad de la Iglesia se fomenta también de una manera especial en los múltiples consejos que el Señor propone en el Evangelio para que los observen sus discípulos, entre los que descuella el precioso don de la gracia divina, que el Padre da a algunos (cf. Mt 19,11; 1Co 7,7) de entregarse más fácilmente sólo a Dios en la virginidad o en el celibato, sin dividir con otro su corazón (cf. 1Co 7,32-34). Esta perfecta continencia por el reino de los cielos, siempre ha sido considerada por la Iglesia en grandísima estima, como señal y estímulo de la caridad y como manantial extraordinario de espiritual fecundidad en el mundo» ${ }^{6}$.

«Por consiguiente, la profesión de los consejos evangélicos aparece como un distintivo que puede y debe atraer eficazmente a todos los miembros de la Iglesia a cumplir sin desfallecimiento los debres de la vocación cristiana. Porque, al no tener el pueblo de Dios una ciudadanía permanente en este mundo, sino que busca la futura, el estado religioso, que deja más libres a sus seguidores frente a los cuidados terrenos, manifiesta mejor a todos los presentes los bienes celestiales - presentes incluso en esta vida - y sobre todo da un testimonio de la vida nueva eterna conseguida por la redención de Cristo y preanuncia la resurrección futura y la gloria del reino celestial. $Y$ ese mismo estado imita más de cerca y representa perpetuamente en la Iglesia aquella forma de vida que el Hijo de Dios escogió al venir al mundo para cumplir la voluntad del Padre, y que dejó propuesta a los discípulos que quisieran seguirle. Finalmente, pone a la vista de todos, de una manera particular, la elevación del reino de Dios sobre todo lo terreno y sus grandes exigencias.... ${ }^{7}$.

Me parece que los párrafos citados son de tal densidad y están cargados

5. VATICANO II, LG, 43a.

6. VATICANO II, LG, 42c.

7. VATICANO $\mathrm{II}, \mathrm{LG}, 44 \mathrm{c}$. 
de tales calidades que ellos deben bastar por sí solos, para crear en nosotros el convencimiento de que la vida religiosa tiene aún vigencia en nuestro mundo. Diría más, recogiendo un pensamiento de J.B. Metz: que precisamente éste es el tiempo de las órdenes religiosas. Más adelante la verdad de estos hechos quedará reflejada de una manera especial, al igual que sus exigencias en el mundo moderno. Por ahora, creo que es suficiente, para resaltar nuestro compromiso frente a la necesidad de fomentar las vocaciones.

$\mathrm{Si}$ a esto añadimos que la gran parte de nuestra comunidad accede al ministerio eclesial, entonces la necesidad de trabajar por las vocaciones adquiere nuevos valores y nuevas exigencias. Valores y exigencias de las que, una vez más, se hace eco la enseñanza del Vaticano II. «Repetidas veces ha traído este sagrado Concilio a lar.memoria de todos la excelencia del orden de los presbiteros en la Iglesia. $Y$ como se asignan a este orden en la renovación de la Iglesia influjos de suma trascendencia y más difíciles cada día, ha parecido muy útil tratar más amplia y profundamente de los presbíteros. Lo que aquí se dice se aplica a todos los presbíteros, en especial a los que se dedican a la cura de almas, haciendo las salvedades debidas con relación a los presbíteros religiosos. Pues los presbíteros, por la ordenación sagrada y por la misión que reciben..., son promovidos pàra servir a Cristo Maestro, Sacerdote y Rey, de cuyo ministerio participan, por el que la Iglesia se constituye constantemente en este mundo Pueblo de Dios, Cuerpo de Cristo y templo del Espíritu Santo" ${ }^{8}$.

La necesidad del ministerio no sólo la resalta el Vaticano II, como acabamos de ver en relación al presbiterado, sino que se pone de relieve en todos los ámbitos de las diversas comunidades cristianas. Lo que nos hace ver su importancia trascendental para la acción evangelizadora en el mundo. En esto hay un auténtico y consolador consenso entre todas las confesiones cristianas. Lo cual es indicio claro de que se trata de un dato de la revelación verdaderamente significativo. Es importante realizar, al respecto, un ramillete de sentencias o pensamientos, con el fin de advertir la importancia que se da al tema del ministerio en otras iglesias cristianas $y$, de este modo, estimular nuestro empeño en la conquista de nuevas vocaciones.

Lutero, el iniciador de la Reforma, afirma con frase lapidaria: «Todos somos sacerdotes, pero no todos son ministros o servidores» ${ }^{9}$. En el escrito «sobre los concilios y las iglesias» (1539), Lutero nombra, tras la Palabra, el bautismo, la Cena y las llaves, los ministerios, como las cinco señales o signos de la Iglesia. «Por amor al Evangelio, dice, es necesario que la Iglesia tenga

8. VATICANO II, PO, 1.

9. Lutero, M. WA 7,28,26. 
ministros, servidores» ${ }^{10}$. Vemos, pues, que en el pensamiento del gran reformador el ministerio ocupa un lugar de excepción, hasta considerarlo como signo de la Iglesia auténtica.

Calvino, el otro gran reformador, y sobre el que el teólogo Ganoczy ha realizado un sugestivo estudio sobre su faceta de teólogo de la Iglesia y del ministerio, es más contundente y expresivo sobre el ministerio que Lutero. "Cristo ha establecido en su Iglesia el ministerio, de tal manera que con su supresión vaya a pique la edificación de la Iglesia " «Para la construcción de la Iglesia (Calvino gusta mucho de usar esta imagen paulina) son necesarios diversos servicios, que tienen la finalidad de anunciar a Cristo y su reinado» ${ }^{12}$. Según la expresión de Calvino, la Iglesia iría a pique, naufragaria, si se suprime el ministerio. Por lo que, como se advierte fácilmente, el ministerio es necesario para la permanencia de la Iglesia.

El Grupo teológico luterano-católico en Estados Unidos se refiere a este tema en los siguientes términos: "Con objeto de que la Iglesia sea lo que Dios quiere de ella, en el mundo y para el mundo, Dios concede dentro de este sacerdocio (el sacerdocio de todo el pueblo de Dios) diversos dones en vistas al ministerio...

El ministerio está con el pueblo de Dios bajo la autoridad de Cristo al mismo tiempo que habla en el nombre de Cristo a su pueblo. Por una parte el ministerio en cuanto parte del ministerio de la Iglesia, está bajo la Palabra y el Espíritu, bajo el juicio y bajo la gracia. Pero tiene también un papel especial dentro del ministerio del pueblo de Dios, a saber, proclamar la Palabra de Dios, administrar los sacramentos, exhortar y corregir» ${ }^{13}$.

La Comisión evangélico/luterana-católico/romana afirma: "La Iglesia, como pueblo de Dios peregrino, no habiendo alcanzado todavía su término escatológico, se ve afectada en este entretiempo del 'ya' $y$ del 'todavía no' por ministerios, estructuras e instituciones que deben contribuir a hacer presente la acción salvadora de Dios en Cristo" ${ }^{14}$.

La Comisión evangélico-luterana-católico-romana afirma: «La Iglesia, del ministerio ordenado es la de servir este sacerdocio de todos los fieles. Igual que cualquiera comunidad humana, la Iglesia necesita una concentración de dirección y unidad, que el Espíritu Santo provee en el ministerio orde-

\footnotetext{
10. LUTERO, M., Sobre los concilios y las iglesias. WA. 50,632,35.

11. Calvino, J., Inst. Chrét. IV, 1,11.

12. Calvino, J., Inst. Chrét. IV, 3,2.

13. Grupo Teológico Luterano-Catolico de Estados Unidos, Eucaristía y Ministerio, nn. 11 y 13.

14. Comisión Internacional Evangélico/Luterana-Católico/Romana, el Evangelio y la lglesia, n. 49.
} 
nado» ${ }^{15}$. El Grupo de Dombes, integrado por teólogos luteranos, reformados y católicos, que recibe su nombre de la abadía de Dombes, en donde se reúne, convocado a la sombra del abate Couturier, su gran iniciador y gran amante del ecumenismo, habla del ministerio en los siguientes términos: "La evangelización, el servicio al mundo por la Iglesia, la edificación de la comunidad requiere actividades muy diversas, permanentes o momentáneas, espontáneas o institucionales.

El Espíritu Santo suscita, por consiguiente, en el pueblo de Dios hombres y mujeres para asumir ministerios diversos y complementarios, que testimonian la fidelidad de Cristo a sus promesas y la riqueza de sus dones» ${ }^{16}$.

Los Institutos ecuménicos alemanes, entre cuyos representantes se encuentran teólogos tan significavos como Hans Küng y Wolfhart Panneberg, afirman: "La predicación del evangelio exigió desde el principio diversidad de servicios: apóstoles, profetas, doctores, presidentes, obispos, diáconos, etc. Todas estas funciones fueron interpretadas en el Nuevo Testamento como llamadas y dones de Dios para el servicio de las comunidades (carismas). Por esto, el servicio de fundación y dirección de las comunidades fue, de acuerdo con las diferentes tradiciones y situaciones, diversamente ejercido, es decir, no exclusivamente en virtud de un mandato expresado por la imposición de las manos de los apóstoles o sus delegados...

Estando destinado el evangelio de Jesucristo a todos los pueblos, la Iglesia ha de suceder a los apóstoles en el servicio del mensaje de Cristo... En este servicio se distinguen los que dirigen de los otros miembros de la comunidad ${ }^{17}$.

El documento de ACCRA, del Consejo Ecuménico de la Iglesias, tiene un relieve especial, ya que es reflejo del pensamiento de muchas iglesias cristianas, entre las cuales se encuemtra la iglesia ortodoxa, tan celosa siempre de las tradiciones eclesiales. Su testimonio al respecto es, por ello, enormemente significativo y valioso. "Aunque una diversidad de dones se manifestara dentro de la Iglesia primitiva, el nuevo testamento sienta como hecho las diferencias del ministerio particular; se establecen distinciones en el servicio. Este ministerio particular era entonces esencial y se convierte en esencial para todo tiempo y toda circunstancia. Este ministerio es ejercido por personas que per-

15. Comisión Internacional Anglicano/Catolico-Romana, Ministerio y ordenación, n. 7.

16. Grupo de Dombes, Para una reconciliación de los ministerios, nn. 17 y 18.

17. Institutos Ecuménicos Alemanes, Reforma y reconocimiento de tos ministerios, $\mathrm{nn} .8$ y 9. 
tenecen a la comunidad, que son llamadas y que reciben los dones y la autoridad para transmitir el testimonio viviente de los apóstoles» ${ }^{18}$.

Todos estos testimonios que, por su abanico de procedencia e ideología, bien se pueden considerar como el sentir de la Iglesia de Cristo sobre el ministerio, refuerzan al máximo la necesidad de cultivar las vocaciones de aquéllos, y también, como dato previo, de buscarlas, que en un futuro próximo o lejano, van a tomar el revelo. Es un deber que nos afecta como comunidad eclesial y como comunidad religiosa. Mientras permanezca el deseo de Cristo: «id por todo el mundo y predicad el evangelio a toda criatura» (cf. Mt 28, 19), y este deseo permanecerá hasta la consumación de los siglos, mientras haya un hombre que salvar, nosotros, como Iglesia y, por fuerza mayor, como comunidad religiosa, tenemos que estar dispuestos a trabajar por todos los medios en el tema de las vocaciones. Nuestra propia vocación, vivida con ilusión y alegría, debe ser un estímulo en esta misma tarea.

4

Mas las cosas no pueden quedar simplemente aquí. Tenemos que trabajar, en diversa forma, por cierto, pero con eficacia, por conseguir vocaciones. Esta es la conclusión, que se deriva, de todo lo anteriormente dicho. Pero este hecho nos enfrenta frontalmente, sin meandros, con un interrogante que es. al mismo tiempo, un reto a nuestra propia condición eclesial. ¿Bastaría, sin más, el simple hecho de la necesidad de servidores en la comunidad eclesial, para dar razón o explicar nuestro proselitismo? Creo que no. Por lo menos, no sería la única ni tampoco la principal de las razones. Es necesario, como elemento esencial, tener en cuenta la calidad o vivencia de nuestro compromiso. Necesitamos vivir en profundidad nuestro compromiso religioso. Sólo así podemos ofrecer a otros un modelo de vida, que pueda llenar sus aspiraciones de seguimiento especial de Cristo.

Esta constatación lleva sin violencia a tratar uno de los puntos más vital, por un lado, y más complejo, por otro, de nuestro compromiso religioso. Se trata de la relación profunda que existe entre vida religiosa y mundo moderno. A ello voy a dedicar algunas reflexiones, siquiera sean, por necesidad de espacio y tiempo, muy breves.

"La renovación de la vida religiosa, dice el teólogo Leonardo Boff, no proviene, sin más, de la simple elaboración de nuevas ideas, de una más o menos acertada interpretación de la regla de los respectivos fundadores o de la mera adaptación de la disciplina a las exigencias de un mundo diferente. La raíz de toda auténtica renovación reside en una nueva y honda experiencia de

18. DOCUMENTO DE ACRA, El ministerio ordenando en una perspectiva ecuménica, n. 13. 
Dios, articulada en el interior de una nueva experiencia del mundo. Sólo en función de tal experiencia podrán y deberán vertebrarse las nuevas constelaciones de ideas, reinterpretarse los valores del pasado, así como buscarse una adecuada presencia en la sociedad y en la Iglesia» ${ }^{19}$.

Las sugestivas palabras de Leonardo Boff nos ponen en pista. Se constata, de entrada, que nuestro mundo es un mundo diferente. Radicalmente diferente. $\mathrm{Y}$ este hecho no puede pasar desapercibido ni puede dejar de influir en la vivencia de nuestro compromiso religioso. «El género humano se halla hoy en un nuevo período de su historia, caracterizado por cambios profundos $y$ acelerados, que progresivamente se extienden al universo entero. Los provoca el hombre con su inteligencia y su actividad creadora; pero recaen luego sobre el hombre, sobre sus juicios y deseos individuales y colectivos, sobre sus modos de pensar y sobre su comportamiento para con las realidades y los hombres con quienes convive. Tan es eso así, que se puede hablar de una verdadera metamorfosis social y cultural, que redunda también sobre la vida religiosa» ${ }^{20}$. Fruto inmediato de esta metamorfosis social y cultural es el nacimiento de un nuevo humanismo, del que el Concilio se hace también eco. «De esta manera somos testigos de que nace un nuevo humanismo, en el que el hombre queda definido principalmente por su responsabilidad hacia sus hermanos y ante la historia» ${ }^{21 .}$

El Vaticano II constata un hecho, la realidad de un mundo nuevo, y lo constata con alegría y optimismo, no exentos de algunas angustias. Frente al mundo moderno, la Iglesia del Vaticano II quiere superar la actitud de enfrentamiento, tantas veces presente en su quehacer histórico, y situarse en una actitud de diálogo. Se da cuenta que para poder dialogar con el mundo moderno es preciso usar un lenguaje común. La Iglesia del Vaticano II así lo reconoce. Usa un lenguaje eminentemente actual, en perfecta armonía con la realidad. Un lenguaje, por otra parte, cargado de mensaje para todos los hombres de buena voluntad. Palabras como "cambio», "nuevo», "dinamismo», «libertad», "conciencia», «ḥistoria», "transformación», "construcción del mundo», "socialización», "humanismo», "densidad propia de las realidades terrenas»... nos están diciendo a gritos que la Iglesia del Vaticano II está hablando un lenguaje nuevo. Un lenguaje que tiene como meta engarzar con la problemática actual y traducir su contenido.

Evidentemente la complejidad de nuestro mundo es grande. Su amplitud

19. Boff, L., Testigos de Dios en el corazón del mundo, Instituto teológico de Vida Religiosa, 21.

20. Vaticano II, GS, $4 \mathrm{~b}$.

21. Vaticano II, GS, 55. 
nos obliga precisamente a reducir nuestros focos de atención. Desde esta perspectiva yo me atrevo a señalar dos realidades que pueden y deben ser dos grandes servicios que los religiosos pueden ofrecer al mundo. A) La experiencia de Dios. B) la preocupación constante por la justicia, reflejada en una más auténtica vivencia del voto de pobreza.

\section{A) La experiencia de Dios}

La ausencia de Dios, con todos los dramáticos problemas humanos que trae consigo, es uno de los aspectos más negativos de nuestro mundo occidental. El Vaticano II se hace eco de esta realidad negativa con acentos impresionantes: «Muchos son, sin embargo, los que hoy día se desentienden del todo de esta íntima y vital unión con Dios o la niegan en forma explícita. Es este ateísmo uno de los fenómenos más graves de nuestro tiempo. ${ }^{22}$.

La Iglesia, y dentro de la misma las comunidades religiosas como avanzadilla que son de la Iglesia, no pueden desentenderse de este fenómeno. Tienen que tomar conciencia primero, $y$, luego, tratar de dar una respuesta positiva y válida al reto del ateísmo. ¿Cómo? El mismo Concilio esboza una respuesta preciosa. "El remedio del ateísmo hay que buscarlo en la exposición adecuada de la doctrina y en la integridad de vida de toda la Iglesia y de sus miembros. A la Iglesia le toca hacer presentes y como visibles a Dios Padre y a su Hijo encarnado, con la continua renovación y purificación propias bajo la acción del Espíritu Santo. Esto se logra principalmente con el testimonio de una fe viva $y$ adulta, educada para poder percibir con lucidez las dificultades $y$ poderlas vencer» ${ }^{23}$.

Dos tareas primordiales se nos proponen a todos los cristianos y, de modo particular, a todos los religiosos. Una, de carácter intelectual. Es preciso hacer una exposición adecuada de la doctrina. Lo cual no se consigue, sino a base de un trabajo constante de estudio. Otra, la integridad de vida, hasta llegar a hacer presentes y como visibles a Dios Padre y a su Hijo encarnado, bajo la guía del Espíritu Santo.

La primera tarea no es nada deleznable y cada cual debe fijarse desde su carisma qué es lo que puede y debe hacer en este sentido. Interesa, no obstante, la segunda, pues es aquí en donde cae muy bien esa experiencia de Dios, de la que se hablaba como servicio estupendo que los religiosos pueden hacer al mundo moderno. Podemos ciertamente hacer tal servicio. $Y$ seguramente estamos obligados a hacerlo. Pero aquí comienzan los problemas, si,

22. Vaticano H, GS, 19a.

23. Vaticano $\|, \mathrm{GS}, 21 \mathrm{c}$. 
de verdad, queremos que nuestro compromiso al respecto no sea totalmente ilusorio. Para llevar a cabo una cosa, es necesario poner los medios. Y el medio insustituible en este como en otros casos es que nosotros poseamos esa experiencia de Dios, que queremos transmitir al mundo. Nadie da lo que no tiene. Nosotros no podemos ofrecer la vivencia de Dios, si Dios no es realmente el sentido y el valor existencial de nuestra vida. $Y$ surge la pregunta: ¿cómo se alcanza esa meta? Me parece que la pregunta no tiene más que una respuesta o, por lo menos, una respuesta cualificada, una respuesta que avalarían todos los hombres que han tenido tal experiencia: La vuelta al interior. Sin esta vuelta al interior, en donde habita la Verdad, y que tiene un nombre propio: oración, caeremos irremediablemente en la vorágine de las cosas del mundo y nada, que merezca la pena, desde nuestra condición religiosa, podremos ofrecer al mundo. Intentaremos, tal vez, ser profetas, pero terminaremos irremediablemente por ser meros funcionarios, auténticos vendedores de palabras que hablan de Dios, pero que no transmiten una experiencia de Dios. $Y$ es que para hablar de Dios, es preciso tener la valentía de hablar primero con Dios. «Orar, dice J.B. Metz, es resistir a la trivialidad aplastante de nuestra vida, es oponerse a la idea de que la vida carece totalmente de objeto en una sociedad de puro cambio y necesidad, en la que decrece la capacidad de llorar y de reír...

La oración puede y debe ser el comienzo de una renovación de la esperanza, de una rebelión contra la creciente desesperanza y la lenta desaparición de todo compromiso que, poco a poco, nos va envolviendo a todos» ${ }^{24}$.

Se podrían añadir muchas más. Pero creo que éstas son suficientes, para llevarnos a un serio examen de conciencia. Seguramente está aquí el gozne de nuestra renovación personal y comunitaria y el mejor servicio que podemos ofrecer a un mundo que, deslumbrado por sus conquistas científicas y espaciales ve con angustia cómo pierde la capacidád de ser feliz y de ver sentido al complejo abanico de su realidad vital.

B) La preocupación constante por la justicia y su relación con nuestra forma de vivir el voto de pobreza

El tema contiene materia suficieńte para toda una jornada de reflexión. Aquí tan sólo se dan unas pinceladas, para llamar la atención sobre una materia que afecta muy directamente $y$ vitalmente a la vida religiosa como signo válido.

Comienzo por transcribir un texto importante del Vaticano II. Está toma-

24. Metz, J.B., Invitación a la oración, «Sal Terrae», Santander 1979, 32,36. 
do de la OT y se refiere a algunos aspectos de la formación que hay que dar a los seminaristas. Dice: «aprendan a apreciar, en general, las virtudes que más se estiman hoy entre los hombres y que recomiendan al ministro de Cristo, como son la sinceridad de alma, la preocupación constante por la justicia... $/ 2$.

El tono del texto evita prácticamente todo comentario. El Concilio recomienda enseñar a los seminaristas en esos años decisivos del seminario la preocupación constante por la justicia. Y dice que es una de las virtudes o realidades sociales más estimadas por los hombres de nuestro tiempo. Los hechos, que observamos a diario, confirman plenamente la afirmación del Concilio. Toda comunidad, que de forma real, se compromete en la lucha por una mayor justicia en el mundo encuentra eco en nuestro mundo y está, de alguna manera, haciendo un apostolado vocacional.

Las formas concretas de expresar la constante preocupación por la justicia pueden ser grandemente variadas y dependen, en gran parte, de la situación en que se mueve la comunidad religiosa. Pero hay algo que parece universalmente válido para todas las comunidades religiosas: es el acercamiento a los pobres, sentirse solidarios, no sólo afectivamente, sino realmente con los pobres, viviendo en profundidad y comprometidamente las exigencias del voto de pobreza. Recordemos un texto magnífico del Concilio Vaticano II. «La pobreza voluntaria para el seguimiento de Cristo, del cual es distintivo hoy sobre todo muy apreciado, ha de ser cultivada diligentemente por los religiosos, $y$, si fuera necesario, ha de manifestarse en formas nuevas ${ }^{26}$.

El Concilio comienza por constatar que estamos ante una forma de seguimiento de Cristo hoy sobre todo muy apreciada. Con lo cual queda bien manifiesto su valor de signo. $\mathrm{Y}$, consiguientemente, su valor testimonial y proselitista. $Y$ con todo, se constata un hecho, que tiene todas las características de ser para los religiosos una voz profética y que además es bastante universal. La forma, en que vive la mayoría de las comunidades la pobreza, no dice nada o dice muy poco a nuestro mundo. Se nos tacha de vivir como ricos. Nosotros no podemos quedar indiferentes ante el hecho, por aquello de que la gente es ignorante o sus juicios suelen estar marcados de anticlericalismo.

Desde una perspectiva responsable, y ahora me refiero ya a nuestras comunidades, tenemos que preguntarnos con acento interpelativo: ¿Por qué sucede esto? La respuesta a este interrogante nos lleva, sin extorsiones, al núcleo de la cuestión. A examinar la forma de vivir y expresar nuestro modo de vivir el voto de pobreza. Para ello se han de tener en cuenta dos niveles: 1) el personal; 2) el comunitario.

25. Vaticano II, OT, 11a.

26. VATICANO II, PC, 13a. 


\section{Nivel personal}

Por ser precisamente personal, tan sólo se pueden hacer algunas referencias vagas. Es como un toque de atención a nuestra conciencia individual. Este toque suena así en palabras de Pablo VI: «los religiosos, efectivamente, deben resplandecer delante de todos por el ejemplo de la verdadera pobreza evangélica.

Por lo cual deben amar la pobreza a la que libremente se obligaron y en el uso de los bienes no basta con depender del superior, sino que los mismos religiosos deben contentarse con lo puramente necesario y deben huir de las comodidades $y$ exquisiteces que enervan el vigor de la vida religiosay ${ }^{27}$. Si se tiene ahora en cuenta la relación antes apuntada, de nuestra vivencia de la pobreza con la lucha o preocupación constante por la justicia, entonces me parecen fenomenales y oportunísimas estas palabras de Gustavo Gutiérrez, el célebre teólogo de la liberación: «no se trata de idealizar la pobreza, sino, por el contrario, de asumirla como lo que es: como un mal, para protestar contra ella y esforzarse por abolirla. Como dice Paul-Ricoeur, no se está realmente con los pobres sino luchando contra la pobreza. Gracias a esta solidadridad - hecha gesto preciso, estilo de vida, ruptura con su clase social de origense podrá, además, contribuir a que los pobres y despojados tomen conciencia de su situación de explotación y busquen liberarse de ella. La pobreza cristiana, expresión de amor, es solidaria con los pobres, y es protesta coritra la pobrezan" ${ }^{28}$.

\section{Nivel comunitario}

Seguramente que es éste, por su complejidad, un tema grandemente apropiado para el diálogo. Más que dar soluciones en unas líneas, imposible por la complejidad del tema, se trata de llamar a las puertas de nuestra conciencia con un tema tan vital para nosotros como es el de la pobreza comunitaria. Pablo VI dice: «además de la pobreza propia de cada uno, no puede descuidarse la pobreza con que debe brillar la misma comunidad, la misma familia religiosa, o sea, toda la corporación» ${ }^{29}$. El Vaticano II nos recuerda: "Aunque los institutos, salvas las reglas y constituciones, tienen derecho a poseer todo lo necesario para la vida temporal y el apostolado, eviten, sin embargo, toda

27. PABlo VI, El papa habla a los religiosos, Confederación española de,religiosos, Madrid 1964, 15.

28. Gutiérrez, G., Teologla de la liberación, Sígueme, Salamanca 192, 30.

29. PABlo VI, El papa habla a los religiosos, Confederación española de religiosos, Madrid $1964,15$. 
apariencia de lujo, de lucro inmoderado, de acumulación de bienes ${ }^{30}$. El documento de Dublín confirma y reafirma la misma línea, poniendo además una nota de actualidad, al referirse a nuestro mundo moderno: "Las desigualdades, que padece nuestro mundo, incluso el mundo cristiano, son una fuerte llamada a nuestro carisma. Si entendemos nuestra vida comunitaria abierta a toda la Iglesia y al mundo, como la entendió S. Agustín, nuestra comunidad de bienes hará participantes también a los hombres de nuestro alrededor. Así evitaremos la cumulación excesiva de bienes y contribuiremos a una mentalización frente al problema social de nuestro tiempo" ${ }^{31}$.

Como se desprende fácilmente de los textos aducidos, el tema de la pobreza comunitaria nos cuestiona y nos interroga. Somos miembros de una comunidad, que se presenta ante el mundo $y$ ante las autoridades de una nación como poseedora de bienes. El hecho en sí es normal. Todo ello da una imagen de lo que somos ante los demás. ¿Responde tal imagen a nuestra profesión de pobres, elegida como forma particular del seguimiento de Cristo pobre? La voz del pueblo parece decir que no. Se nos considera ricos, justa o injustamente. $Y$ esto es muy grave para el valor testimonial de la vida religiosa.

Surgen, ante esta realidad, una serie de preguntas, a las que tiene que responder, por nuestra parte, una actitud concreta. ¿Brilla nuestra comunidad, como tal, por una auténtica pobreza? ¿Evitamos toda apariencia de lujo? ¿De lucro inmoderado? ¿De acumulación de bienes? ¿Hacemos participar a los hombres necesitados de nuestro entorno de nuestros bienes?. Son muchos interrogantes y seguramente que tanto vosotros como yo no estemos en condiciones de responder a alguno de ellos e incluso a ninguno. Pero aquí radica precisamente nuestra responsabilidad. En un tema que nos afecta tanto a nivel comunitario, pues nosotros somos la comunidad, hemos de intentar por todos los medios posibles obtener una información exacta a nivel provincial de nuestros ingresos, de nuestros gastos y del empleo del remanente, si lo hay. Y ello no debe responder a una acción policial. Confiamos en quienes tienen una misión directa en este campo. Ello responde única y exclusivamente a la necesidad y a la obligación, que todos tenemos, de colaborar en la conquista de una pobreza comunitaria, tan decisiva para nuestro compromiso evangélico y para que la vida religiosa adquiera e/ valor de signo, del que se encuentra tan necesitada.

Quiero terminar esta exposición con unas hermosas palabras de Mons. Sebastián Aguilar, obispo de León. "Un grupo de gente pobre es sencillamente un grupo de gente que: 1) vive de su trabajo; 2) pone en común sus bienes

30. Vaticano I, PC, $13 f$.

31. DD. Capítulo general intermedio de la Orden agustiniana, Dublín 1974, 6. 
sin apropiaciones ni discriminaciones de ninguna clase; 3) ayuda en lo que puede a quienes padecen necesidad; 4) trata de enseñar el desprendimiento como un camino para la paz y la fraternidad humana; 5) con su vida y sus obras combate el egoísmo y la avaricia en favor de los oprimidos. Todo esto 6) como expresión y ejercicio de una voluntad determinada de vivir enteramente y de manera eficaz el programa cristiano de las bienaventuranzas» ${ }^{32}$.

Benito Dominguez SÁNCHEZ

32. Sebastián, F. Citado por NiCOlAs, A., El horizonte de la esperanza. La vida religiosa hoy, Sígueme, Salamanca 198, 154. 